\title{
How can demography inform health policy?
}

\author{
TIZIANA LEONE* \\ Senior Research Fellow, LSE Health, London School of Economics, London, UK
}

\begin{abstract}
Demography's contribution to health policy debates comes from the study of population dynamics relating to fertility, mortality and migration. The aim of this article is to stress how vital a correct understanding of population dynamics is for health policy and planning. The article first highlights some of the major contributions demographers have made to debates about health, particularly where they have helped to overcome misconceptions. It then discusses two prominent issues: population ageing in the developed world and population growth in developing countries.
\end{abstract}

Demography is usually defined as the study of human populations - their size, growth, density and distribution - and statistics regarding birth, marriage, disease and death. Demographers have often suffered from 'identity' crises when trying to locate themselves within a scientific discipline. By nature, demography is a multidisciplinary subject, which emphasises rigorous data analysis using specific methods accompanied by theory that is often associated with sociology, statistics, anthropology, economics and public health, among others. According to some scholars, health demography has become a discipline in its own right (Pol and Thomas, 2001).

Undoubtedly, demography's major contribution to health policy comes from the study of population dynamics in the form of the determinants of fertility, mortality and migration. Within these areas of study, demographers have often been involved in the analysis of family dynamics, kinship effects and child development. In the study of mortality, demographers are usually more concerned with its implications for overall population size and structure, and consequently tend to ignore rare causes of death.

What is sometimes less clear is how demographers contribute to health policy debates. The aim of this article is to stress how a correct understanding of population dynamics is vital for health policy and planning. The article first highlights some of the major contributions demographers have made to debates about health, particularly where they have helped to overcome misconceptions. It then discusses, in more depth, two issues that I believe to be among the most prominent in these debates: population ageing in the developed world and population growth in developing countries.

*Correspondence to: Dr Tiziana Leone, LSE Health, London School of Economics, Houghton Street, London WC2A 2AE, UK. Email: t.leone@lse.ac.uk 


\section{Demographers and health}

Health policy development involves three stages: identifying the major disease problems, designing health care systems and defining what governments can do using the full range of policy instruments (Jamison and Mosley, 1991). Coherent health policies need to be strong in all three areas. Demographers have been crucial in the first stage, since population changes are a key component of changing health needs. Demographic analysis looks at behavioural changes in the population and how these might change a population's structure (age) and composition (gender, race, and so on) in the medium and long term. Demographers have also helped in developing public health programmes and designing instruments to monitor and evaluate the long-term goals of these programmes particularly those targeted at older people and infants (Nam, 1979).

Additionally, demographers have contributed to the debate on differences in mortality by sex and socio-economic status. While biology is a fundamental component, social and behavioural factors have proved to be as important (Marmot et al., 1995). For example, life-course demography has been key to understanding the impact of parental choices and behaviours on child development, while longitudinal and panel studies have been vital in elucidating lone parenthood effects on child health and assessing the impact of HIV/AIDS-related deaths on household composition, kinship and informal care (Ford and Hosegood, 2005).

\section{The demographic transition}

The main contribution of demographic thinking to wider debates about population change is the demographic transition theory. This has had a deep impact on the work of national and international agencies in both the developed and the developing world for the last 50 years. The theory identifies different stages of demographic transition based on fertility and mortality levels, ranging from stage one, when fertility and mortality are balanced at very high levels; to stage two, when mortality starts to decrease and fertility subsequently declines; to the third stage, when population growth is close to zero, with low birth and death rates. This pattern has been experienced by every country in the developed world and has been crucial for studies of the relationship between fertility and mortality. One of the major implications of the developed-world demographic studies based on this model has been the realisation that fertility decline in the developing world is not necessarily dependent on increasing industrialisation or modernisation, as it was in developed countries (Caldwell, 1976).

\section{The lifespan debate}

The contribution of demographers to the current debate on whether human lifespan is fixed has also been crucial. Life expectancy has increased steadily over the last 140 years in many countries and some have argued that there is a fixed 'maximum' 
human lifespan (Hayflick, 1986). Thus far, however, the assertion of the existence of a maximum lifespan based on biological arguments has had little scientific basis (Oeppen and Vaupel, 2002). Oeppen and Vaupel (2002) have shown that continuous improvement in life expectancy has not slowed, and that life expectancy has not yet reached its maximum threshold. Since it is not feasible at this stage to set the 'maximum', as previously believed, health planners will need to allow for continuous increases in the numbers and proportions of older people in the decades to come.

\section{Sources of data and methods}

Demographers have been active in collecting nationally representative data and in developing new methods that have been fundamental to the analysis of health outcomes. Census and vital registration remain among the main tools used to collect data on fertility and mortality, and population registers are increasingly becoming the most commonly used data source. Datasets originally collected for demographic purposes, such as the World Fertility Survey, ${ }^{1}$ the Demographic and Health Survey ${ }^{2}$ programmes in developing countries and the Fertility and Family Survey ${ }^{3}$ programme in Europe, among others, have been widely used to understand health trends and determinants. For example, the development of methods for evaluating and adjusting incomplete data has been essential to the analysis of child and adult mortality in developing countries (United Nations, 2002), and the work of William Brass at the London School of Hygiene and Tropical Medicine has been seminal in devising methods that allow the indirect estimation of mortality using census data in the absence of complete vital statistics. Given that vital statistics in sub-Saharan Africa are far from complete, there is a further need to develop demographic techniques to accommodate current mortality patterns, such as those pertaining to HIV/AIDS. Almost all estimates of population change in less developed countries are based on demographic methods applied to simple survey questions, such as the number of older people and whether children, siblings and parents are alive.

In addition to empirical analyses, demographers have led methodological developments in the analysis of mortality with frailty models, given that medical models cannot fully explain changes in mortality over time. Finally, an important demographic contribution has been the application and continuing development of life tables methods used in epidemiological and sociological analyses.

\section{Low fertility and ageing: a demographic time bomb or a damp squib?}

Data from the United Nations (UN) Population Division (2007) show that between 1950 and 2005, the population aged 60 years and over has more than

1 At the time, this was the world's largest survey programme. It was coordinated by the International Statistical Institute in the Netherlands and funded by two US-based agencies.

2 Funded by United States Agency for International Development (USAID).

3 Coordinated by the United Nations. 


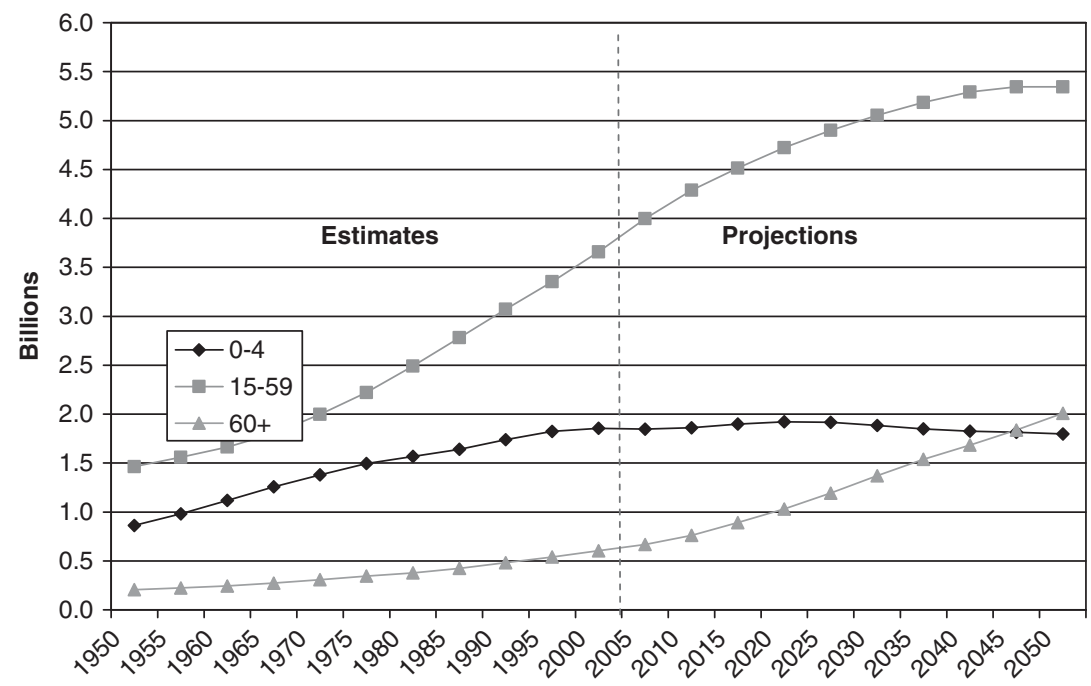

Figure 1. World population by age group, 1950-2050.

Source: United Nations Population Division (2007).

tripled to 700 million in 2006 (United Nations, 2007). By 2050, it is projected that there will be two billion older persons (Figure 1).

Ageing is one of the most prominent issues demographers have focused on in the last decade. A major task for demographers has been to remove the preconceptions and inaccuracies that surround the issue, particularly regarding future dependency ratios. ${ }^{4}$ Population ageing arises when the increasing number of older persons (conventionally considered as those aged either 60 or 65 years and over) in the population is accompanied by reductions in the proportion of children, and the average age of the population increases. UN projections (United Nations, 2007) show that the number of older people worldwide is expected to overtake the number of children for the first time in 2047 (Figure 1). In the more developed parts of the world, where population ageing is more advanced, the number of children dropped below that of older persons in 1998 (Figure 2).

It is often assumed that population ageing is due to improvements in mortality. However, one of the counterintuitive findings of demographic research is that population ageing is primarily caused by declining fertility (Coale, 1964). Indeed, improvements in mortality make population structures younger rather than older, since in a growth period, improvements in mortality levels are faster and more prominent in younger than in older generations. Thus, improved mortality in developing countries will initially make the population structurally

4 Demographic dependency ratios are calculated by dividing the population aged 0-14 (or 0-19) plus the population aged $60+$ (or $65+$ ) by the remaining population (conventionally called the working age population). The old age dependency ratio is calculated as the ratio of older people to the working age population. 


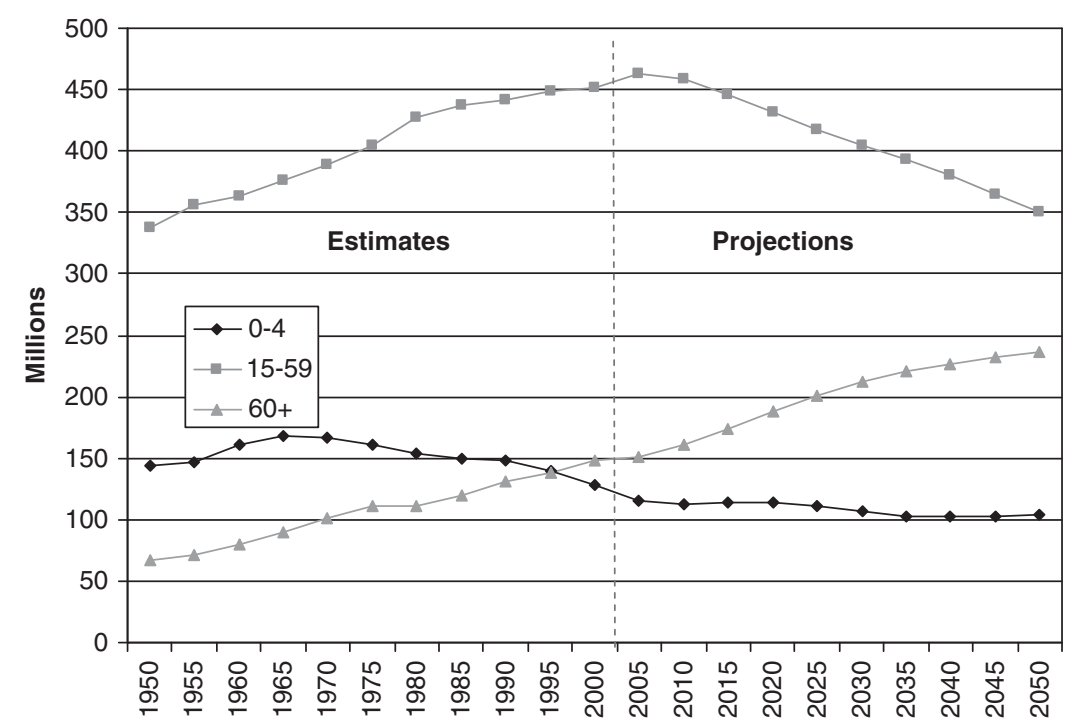

Figure 2. Europe's population by age group, 1950-2050

Source: United Nations Population Division (2007).

younger. Only in the most developed societies does 'ageing from the top' (i.e. increasing life expectancy) become an issue (see below).

There is a wealth of research on the implications of ageing for social policy in general and for health policy in particular. Ageing is a key challenge for the future because it is likely to put more pressure on health care financing. The main issue here is that increased life expectancy is not necessarily linked to better health status, so people may live longer but may also experience longer periods of ill health. However, growing evidence shows that traditional predictions of the impact of ageing on health care costs have been overstated. Increasing demographic pressure on health care costs is partially counteracted by the postponement of death-related hospital costs to later in life, when they are usually lower (Seshamani and Gray, 2004). This makes an ageing 'crisis' seem less likely.

Where the population is just starting to age, older people are usually less educated, generally have less knowledge of the type of services they are entitled to and are less likely to have secured health insurance than in developed societies where ageing started earlier (Lloyd-Sherlock, 2000). This finding is particularly important for developing countries: first, because there is concern that health care systems might not be sufficiently prepared to cope with the health needs of older people; and second, because steep declines in fertility have already occurred, which means that increasing improvements in life expectancy will lead to much more rapid ageing. The rise of non-communicable diseases also adds to already stretched resources. Less developed countries therefore face a so-called 
'double burden of disease' in which levels of obesity, diabetes, cardiovascular disease, chronic respiratory disease and cancer increase alongside the steady pace of common infectious diseases such as tuberculosis and HIV/AIDS. Ageing and the rise of chronic diseases will exacerbate resource constraints in developing regions.

The move to an ageing society involves a large shift in the burden of providing income support and care giving. Women still provide most childcare and care for older people in Western societies (Robine et al., 2008). More research is needed on the impact of delayed fertility on caring for older people. In addition, with a rising proportion of childless people entering old age over the next two decades, providing care for these groups will emerge as an increasing challenge.

Nearly all of the European nations have experienced long-term declines in fertility for the past century or so and a consequent ageing of their populations, but recognition of the implications of population ageing have only recently attracted significant interest. The level of ageing differs across Europe, with countries like Italy, Germany and Spain being particularly affected due to their lower levels of fertility and immigration compared with Scandinavian countries. Lower fertility means fewer siblings, and increases in childlessness diminish the potential for family networks to provide social, psychological and economic support. However, research shows that even in countries with the lowest fertility, levels of childlessness have been modest and constant (almost 50\% of women have at least one child in most cases) (Kohler et al., 2006). Women want to have at least one child but delay doing so more than in the past. As a result, increases in dependency ratios in Europe will be lower than expected. Nonetheless, low levels of fertility are likely to persist in the coming decades and will have a big impact on the population age structure and the social care systems of the countries affected (Kohler et al., 2006). Understanding how age structures develop in the future will be crucial to understanding the health care needs of ageing societies.

Robine et al. (2007) focus on the intergenerational support needed for the oldest people. In particular, they highlight the importance of considering long-term care or capacity within families to care for older people. As noted above, most studies usually rely on the demographic dependency ratio, given by the proportion of over 65 -year-olds over the proportion of persons of working age, as a measure of the extent of ageing. Given the increasing lengthening of life expectancy and the issues linked to quality of life at older ages, this ratio does not reflect the extent of the problem. The so-called 'sandwich' generation (in their mid-50s) will play a great role in the level of support offered to older people. It has therefore been suggested that the oldest old support ratio (i.e. the ratio of the population aged between 50 and 74 to those aged over 85 ) should be used when analysing the level of ageing of the population. The study by Robine et al. (2008) shows how in countries such as Switzerland and the United States, the oldest old support ratio has declined steadily (alongside an increase in the dependency ratio), which could indicate a decline in the availability of informal care. In other words, the 50-74-year-old generation 
will not be sufficiently large to look after the increasing number of over 85 -yearolds. Obviously, the use of formal care will increase (unless the average contribution per carer increases), but it will not be able to replace the flexibility, convenience and, for the 'public purse', cheapness of informal care.

Another factor that needs more attention is analysis of the partnership experiences of older people. The current generation of older people has had high levels of marriage and low levels of divorce. When those born in the 1960s, who have experienced high rates of partnership breakdown, childlessness and solo living, start to age, the issue of the availability of informal care will be more pertinent. It is important to stress, however, that alarmist tones of 'crisis' are not justified at present, since there is still strong support available from partners and this particular generation will not reach retirement age for another 30 years.

Pro-natalist policies and migration have been suggested as possible solutions to ageing in developed countries (United Nations, 2007). However, pro-natalist policies do not always take into account the timescale of population dynamics. There is a need for more research on the timing of childbearing as well as on future levels of fertility in the current 'lowest-low' fertility countries (i.e. those with a total fertility rate below 1.3 children). Fertility is actually rising in some of the lowest fertility countries, as evidence collected by the Population Reference Bureau shows (Haub, 2008). Although migrants are usually of working age and would rebalance the age structure of ageing populations, rigorous demographic analysis shows that immigration cannot be a long-term solution (Keely, 2001). The level of migration needed to compensate for current levels of fertility might be unsustainable for the host countries, since migrants also need services (health, education, and so on) for themselves and their families. Instead, increasing the participation of women and older people in the labour market in countries like Italy or Spain, for example, could be more effective than migration in meeting the problems of population ageing (Keely, 2001).

\section{The role of demography in health policy in developing countries}

While population ageing has been a topic of considerable interest in developed countries, the great majority of the increase in the numbers of older people in the years to come will occur in developing countries. However, in these societies, population growth remains the prominent issue, with major implications for health policy.

There is a wealth of evidence on the relationship between health and development (Phillips and Verhasselt, 1994). The literature on the topic is rich and highlights the fact that establishing causality is not always straightforward. One element of this relationship is the demographic dividend: the decline in fertility, which helped to reduce the dependency ratio, leading to less need for investment in younger age groups (immunisation, health costs) and increasing productivity (Lee and Mason, 2006). Demographers have played a fundamental role in 
identifying the link between poor health and demographic transition, and were among those who rejected the assumption that improvements in health must necessarily be the result of increases in income (Bloom and Canning, 2000). In areas such as sub-Saharan Africa, demographers are focusing their attention on how fertility may decline in the era of HIV/AIDS due to the delayed onset of sexual relations and age at first union, reduced premarital sexual relations and remarriage, increased marital dissolution and lower fertility among HIV positive women. However, the most important contribution of demographers to the development agenda at the moment is in the debate on population growth.

\section{Population growth}

The less developed regions' population is currently growing at a rate of $1.4 \%$ per year (Figure 3), and growth rates in Africa as a whole exceed 2.3\% per year, the highest growth rate of any major area (United Nations Population Division, 2006). In recent decades much attention has been given to the mortality implications of HIV/AIDS pandemics, but the continuing importance of population growth has been highlighted by an increasing number of academic and policy papers dedicated to this issue (De Souza et al., 2003; Cleland et al., 2006; All Party Parliamentary Group on Population, 2007). There are two key issues: population growth is slowing down the achievement of the Millennium Development Goals (MDGs) and has a detrimental impact on the environment and food security. Demographers are calling upon governments to pay more attention to population growth issues in general and family planning in particular, which are not as prominent now as they were after the UN Conference on Population and Development held in Cairo, in 1994.

Regardless of their limitations, the MDGs have drawn attention to population growth and family planning issues. The report by the UK parliamentary enquiry, in particular, highlights how, as the population grows, so does the demand for health care (All Party Parliamentary Group on Population, 2007). The report calls for an increase in funding if the MDGs are to be achieved and stresses that, for example, maternal mortality needs to be addressed urgently because one woman still dies every minute from causes related to pregnancy and childbirth. Lack of family planning means increasing unwanted pregnancies and consequently, unsafe abortions in limited, often illegal settings.

The stalling of the fertility decline in many sub-Saharan countries is also a cause for concern. Many claim that the policy focus has gradually shifted towards HIV/AIDS at the expense of other health-related and population growth issues (Shiffman, 2008). This reflects the fact that a steady decline in fertility was taken for granted and that there has been a lack of collaboration between demographers and economists in trying to cost issues such as family planning and maternal mortality. I believe that while a more balanced approach to addressing population growth is needed, there is also a need to learn from 


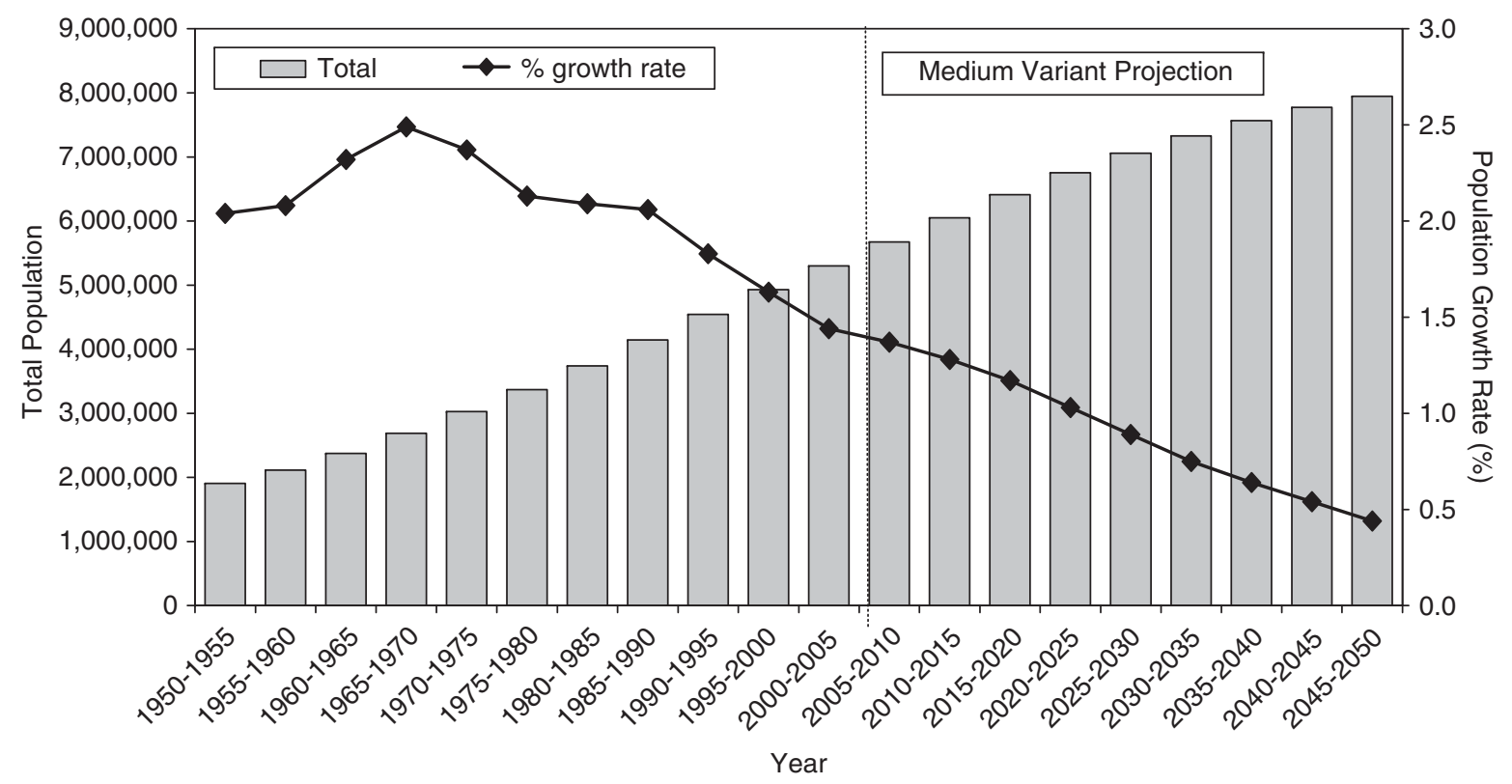

Figure 3. Population trends, less developed regions, 1950-2050

Source: UN World Population Prospects (2006 Revision). 
some of the successes achieved by HIV/AIDS campaigners. The economic analysis of the impact of HIV/AIDS on health care systems and households has been one of the major successes of the campaign to obtain support from donors and to get governments on board. Similarly, demographers should engage more with other social scientists on population growth and its impact on development, as was done so successfully when incorporating lessons about the role of birth spacing on child mortality derived from fertility and family surveys.

\section{Conclusion}

Looking at the World Health Organization's definition of health as "a state of complete physical, mental and social well-being and not merely the absence of disease or infirmity", the socio-demographic components can be easily identified. The role of demographers is wider than a mere study of mortality trends and is centred on the analysis of the impact of population dynamics on health and health care. Demographers have shown how population ageing is mainly caused by an overall change in age structure determined by fertility; only a minor aspect of this is due to increasing life expectancy. When considering appropriate health policy for health care systems to cope with increasing demand for care for older people, it is important to think not just about the higher number of older people in the population, but about who will care for them. Analysis of age structures and marriage patterns will also be crucial because 50-74-year-olds play a fundamental role in providing informal care. Better understanding of the timing of fertility and life expectancy, migration and marriage dynamics over the next 50 years will be vital for health policy planners. Similarly, in developing countries, where continuous population growth is the result of steady fertility levels in a period of decreasing mortality, analysis of fertility trends is crucial to understanding the impact that population growth will have on development and on health care systems.

\section{Acknowledgement}

I would like to thank Professor Mike Murphy for his valuable comments on an earlier draft of this article.

\section{References}

All Party Parliamentary Group On Population, D. A. R. H. (2007), Return of the Population Growth Factor, London, UK: All Party Parliamentary Group on Population, Development and Reproductive Health.

Bloom, D. E. and D. Canning (2000), 'Public health: the health and wealth of nations', Science, 287: 1207-1209. 
Caldwell, J. C. (1976), 'Toward a restatement of demographic transition theory', Population and Development Review, 2: 321-366.

Cleland, J., S. Berstein, A. Ezeh, A. Faundes, A. Glasier and J. Innis (2006), 'Family planning: the unfinished agenda', Lancet, 368: 1810-1827.

Coale, A. (1964), 'How a Population Ages or Grows Younger', in R. Freedman (ed.), Population: The Vital Revolution, Garden City, NY: Doubleday.

De Souza, R.-M., J. S. Williams and F. A. B. Meyerson (2003), Critical Links: Population, Health and Environment, Washington, DC: Population Reference Bureau.

Ford, K. and V. Hosegood (2005), 'AIDS mortality and the mobility of children in Kwazulu Natal, South Africa', Demography, 42: 757-768.

Haub, C. (2008), 'Tracking Trends in Low Fertility Countries: An Uptick in Europe?', in Population Reference Bureau (ed.), Retrieved September 2008, http://www.prb.org/ Articles/2008/tfrtrendsept08.aspx

Hayflick, L. (1986), 'The biological constraints of human aging: implications for health policy, the human lifespan', in K. G. Andreoli, L. A. Musser and S. J. Reiser (eds), Health Care for the Elderly: Regional Responses to National Policy Issues, Houston, USA: Haworth Press.

Jamison, D. T. and W. H. Mosley (1991), 'Disease control priorities in developing countries: health policy responses to epidemiological change', American Journal of Public Health, 81: 15-22.

Keely, C. (2001), 'Replacement migration: the wave of the future?', International Migration, 39: 103-110.

Kohler, H.-P., F. C. Billari and J. A. Ortega (2006), 'Low Fertility in Europe: Causes, Implications and Policy Options', in F. R. Harris (ed.), The Baby Bust: Who Will Do the Work? Who Will Pay the Taxes?, Lanham, MD: Rowman \& Littlefield Publishers.

Lee, R. and A. Mason (2006), 'What is the demographic dividend?', Finance and Development, 26: 16-17.

Lloyd-Sherlock, P. (2000), 'Population ageing in developed and developing regions: implications for health policy', Social Science and Medicine, 51: 887-895.

Marmot, M. G., M. Bobak and G. Davey Smith (1995), 'Explanations for Social Inequalities in Health', in B. C. Amick, S. Levine, A. R. Tarlov and D. C. Walsh (eds), Society and Health, Oxford: Oxford University Press.

Nam, C. B. (1979), 'The progress of demography as a scientific discipline', Demography, 16: 485-492.

Oeppen, J. and J. W. Vaupel (2002), 'Enhanced: broken limits to life expectancy', Science, 296: 1029-1031.

Phillips, D. R. and Y. Verhasselt (1994), Health and Development, London, New York: Routledge.

Pol, L. G. and R. K. Thomas (2001), The Demography of Health and Health Care, New York: Kluwer Academic/Plenum Publisher.

Robine, J.-M., J.-P. Michel and F. R. Herrmann (2007), 'Who will care for the oldest people in our ageing society', British Medical Journal, 334: 570-571.

Seshamani, M. and A. Gray (2004), 'Time to death and health expenditure: an improved model for the impact of demographic change on health care costs', Age Ageing, 33: 556-561.

Shiffman, J. (2008), 'Has donor prioritization of HIV/AIDS displaced aid for other health issues', Health Policy and Planning, 23: 95-100.

United Nations (2002), Methods for Estimating Adult Mortality, New York, USA: United Nations.

United Nations (2007), World Population Ageing 2007, New York: UNDesa.

United Nations Population Division (2007), UN Population Prospects, New York: UN. 